\title{
Modernization of Russian environmental efficiency in the green economy
}

\author{
Galina Dovlatova, ${ }^{1, *}$, Araksi Dovlatova ${ }^{2}$, Anna Smakhtina $^{1}$, Olga Tkachova $^{1}$, Anatoliy \\ Chistyakov $^{1}$, Olga Bondarenko ${ }^{1}$, Anton Agafonov ${ }^{1}$, and Nika Plotnikova ${ }^{3}$ \\ ${ }^{1}$ Platov South-Russia State Polytechnic University (NPI), Lenin square.1, 346500 Shakhty, Russia \\ ${ }^{2}$ Southern Federal University, Bolshaya Sadovaya street, 105/42, 344006 Rostov-on-Don, Russia \\ ${ }^{3}$ Don State Technical University, Gagarina square, 1, 344010, Rostov-on-Don, Russia
}

\begin{abstract}
In the article the authors propose a theoretical rethinking of the traditional understanding of environmental management and the practical application of the Japanese method of «Lean production» to sustainable development of Russian enterprises allows not only to adapt them to innovative changes based on innovative generations a dynamic and effective global environmental and managerial technologies, and solutions covering the world in recent decades, but also to make changes by ensuring the further sustainable socio-economic development of Russia in line with the transition of the traditional economy to a green economy through the introduction of the international environmental standard ISO 14000. In today's unstable economic conditions, enterprises constantly expose their environmental potential to the risks of both exogenous and endogenous factors. From our point of view, the key tool for the stable and competitive development of the national green economy is technological green innovations, their development and implementation in lean production processes. It is advisable to use a system of indicators of all the potentials of the enterprise, such as environmental, economic, innovative, human and intellectual, which takes into account the amount of accumulated resources, the degree of use of potential opportunities for implementation in the production lean process.
\end{abstract}

\section{Introduction}

The "green" economy is aimed at preserving the natural environment, as this is the most important condition for the development of the Russian economy. Within its framework, economic growth is accepted as a dependent component of the environment and its sustainable development.

We should not forget that the green economy is aimed at preserving the natural environment, as this is the most important condition for the development of the Russian economy. In this case, economic growth is taken as a dependent component of the environment.

That is, the sustainable development of social and economic systems should be aimed at stability without harming the natural environment.

\footnotetext{
* Corresponding author: dovlatyan79@mail.ru
} 
Researchers theorist R. N. Batavia Environmental aspects of "green economy" economic growth in Russia: «It is necessary to reveal the characteristics and criteria of the stable development due to the highest possible use of internal resources and determination of the degree of job satisfaction by means of the permanent staff monitoring for the increase of their green business activity» [1].

In particular, the problems of social and economic effectiveness (practical values of the management theory) are not solved. There are no scientifically based criteria of the job assessment of enterprises.

At present, the problem of a business activity assessment has not been fully researched, as each scientist suggests various methods of calculation of its indices, which, in our opinion, do not completely reflect the general effectiveness of work of a particular enterprise taking into consideration the specific character of the branch of industry. The problems of a business activity assessment are considered in the scientific works by foreign academic economists such as Alchian A Demsetz H., K.D.Bacon R., Eltis W., Feldstein M., Hayek F., Parker D. According to the scientists, a business activity is the effective use of assets trusted by the owners by managers. It is obvious that these characteristics refer exactly to a business activity but not only to the current activity of an organization [2-6].

Scientific works by Russian scientists E. Kolbachev, T. Kolbacheva, G. Romanova, T. Saveleva, M. Pleshko, A. Pankratenko, O. Tkacheva, E. Popova, A. Sukhova, E. Grevtseva V., Karashchenko: are devoted to the research of the analytic aspects of enterprise management and to the issues of the assessment of the level of a business activity of enterprises in particular, where the institutional approach is the approach in which the number of phenomena green economic behavior of the subjects of the local market in the region is considered [9-18].

We should particularly distinguish such scientists as S. Tsvetcova, V. Rabotyanskaya, S. Bayzulayev, M. Zakhokhova, A. Smetanko, B. Bidova, A. Usanov, Ju. Butyrina, N. Yarychiv, V. Kuznetsov, V. Prokhorova, V. Chernikova, T. Anopchenko, N. Kulikova, E. Akhmetshin, K. Kovalenko who try to find the responses to modern industrial challenges coming from structural reproductive processes [4, 8, 9-17].

The most required for the modernization of the national economy are the problems of the state-private partnership and mechanisms of its financing, as it is stated in the works by Nagoev A., Akhmetshin E., Kovalenko K, Polyakova A., Erzinkyan E., Murzagalina G. Batova B., Bischekova F., Hokonova M. [3, 8, 9,13-16].

The American scientist M. Porter avoids examining the branches of industry that greatly depend on natural resources in his research on country competitiveness because he thinks that such branches do not form the core of economy development. In his opinion, the heart of economy are small mobile companies. He also promotes a cluster approach in economy and points out that the competitiveness of large companies is mostly determined by the competitiveness of their economic environment, the existence of flexible enterprise structures of small and medium-sized businesses allowing the formation of new innovative growing points in the cluster [1]. To our mind, these flexible business structures in the economic sphere are service enterprises. Integrating into the reproductive process as its intermediate part service enterprises form the non-material infrastructure providing the accumulation of science and best practices in the sphere of technology, management, labour organization, etc. and also a diffusion of innovations within the framework of the whole economy in general.

The management and innovative activity on micro level is an integrative process in which all parts of an enterprise are involved. The scientist W. Rice - Johnston noted: "When a goal is set for you, you take full responsibility for the task and the successful achievement of this goal" [2].

Examining a foreign experience of the formation of the management activity it is important to note its interrelation with the organized culture of an enterprise. The culture 
consists of mutual customs, values, norms, relations and behaviour, which have been worked out during the certain period of time and can help make the enterprise unique. The management is responsible to provide the prosperous activity of the enterprise and the achievement of its goals by taking into consideration different participants, regulatory authorities and laws.

Researchers theorists Nagoev A., Akhmetshin E., Kovalenko K., Polyakova A., Erzinkyan E., Murzagalina G. Batova B., Bischekova F., Hokonova M. Cherkesova E., Breusova E., Savchishkina E. interpret a business activity of an enterprise as the assessment determining the effectiveness of the capital management that the enterprise has at its disposal $[8,11,16-18]$.

In the national scientific literature, the innovative process is the transformation of scientific knowledge into innovation that is the creation, assimilation and introduction of the innovations. This interpretation means that taking into account tough competition the key instrument of the innovative process is the result ready for the introduction into the industrial process and having a commercial profit (from the modernization of a product to a new invention and a final patent). The Russian experience shows that, in fact, there are patents developed by scientific groups, but they are not ready for the realization in business sphere because of the insufficient interaction from both sides.

Due to various reasons many enterprises today ignore priority directions of the state programs of development in this field for the creation of their own innovative technologies which will possess special features and originality and can firstly be successfully used for making the production required at the market and secondly for selling technologies to other enterprises to stabilize their financial position. The experience shows that the patents received at higher school and developed by scientific groups are not always required for the realization in business sphere due to different reasons and because of insufficient interaction of the sides.

Taking into consideration a considerable contribution of scientists into the solution of theoretical and methodological problems of the formation and development of enterprise competitiveness and creation of stable positions, it is necessary to point out that actualization and perfection of methodological apparatus for the working-out of management decisions for the development of technological innovations is required in modern conditions and has become the basis for the choice of the scientific problem in many countries.

\section{Materials and methods}

For the analysis of this problem, theoretical and empirical methods, quantitative and qualitative analysis methods, data aggregation methods, expert evaluation method, classification and structuring of information method, comparison method, reference and statistical data.

From all mentioned above it can be concluded that in reality there is an innovative breakthrough, availability of patents and licenses but they are not used enough. In other words, scientific groups and the industrial break-through in industry are quite separate. There is low motivation of interaction between workers. In our opinion, it is necessary to work out some mechanism of actions from developing to introduction of innovations contributing to the increase of innovative and business activity of human resources of an enterprise and the industry in general.

Modernization of the national economy by means of the increase of an innovative and business activity of the inner environment of enterprises aspiring to innovative changes requires developing and introduction of technological innovations. We suggest using the term of technological innovations as a particular final result of the innovative activity in the form of technological effectiveness (evaluating category) related to the ratio of the result value to the cost value. 
The succession of the developing the product innovation, determination of its value at the beginning and at the end of the industrial process and the formation of an advanced technological innovation with the effectiveness on the basis of the quality management and the process approach to management is suggested.

Today we can see that only a wide national dialogue connecting the executive and legislative branches of the state power with the private sector and universities is able to give real productive results.

However, there is some disbalance in the innovative development of the economy of enterprises, branches of industry and the country. To eliminate this disbalance is the priority direction of the state scientific and technological policy, because the state should supplement the market, as "the market functions better in the institutional environment, which determines the rules of free competition" admitting the significance and often complete irreplaceability of the state support of the scientific and technological progress by the market.

For the effective and stable development of the activity of industrial enterprises, it is useful to use methodology and instruments of project, industrial and personnel management, as the right choice of the particular innovative instruments provide high economic and social effectiveness of the activity of enterprises, industry and the social and economic development of the country on the whole. The key instrument is the monitoring for the identification of innovative opportunities. It will allow to work out an effective mechanism of the strategic long-term management.

Development of new technologies and products and the introduction of innovations are the attributes of any competitive enterprise. Its functioning and development in the conditions of a toughening competition is appropriate to call innovative-oriented. It is the innovative potential of an enterprise and its realization by means of the strategy of the innovative development that become the key factor of the preservation of its position at the market, winning of new market niches and getting maximum profit.

\section{Results}

Based on the study of methodology "The Global Competitiveness Report" by K. Schwab the points of the decrease in the social and economic indices of Russia were revealed [7]. In our opinion, they have a negative impact on many branches of the Russian economy, including the potential for innovations, the quality of research institutions, expenses of companies on research and technological development, public purchases of high-technology production, patent certification applications for 2017-2018 (figure 1).

According to picture 1, the innovative activity in Russia is characterized by rather low results during the period of 2017-2018 in spite of its leading position in the world rate of natural resources.

There is a low potential for innovations from human resources; a low motivation of the staff; the shortage of personal financial resources and the lack of state financial support; the cost of innovations; a financial risk; a low interest in cooperation between universities and industry in the sphere of the research and technological development.

Let us examine the rating of the countries according to the level of their preparedness to technological innovations taking into consideration the following indices: availability of upto-date technologies, absorption of technologies at the firm level, foreign direct investment (FDI) and technology transfer, Internet users (percentage of the country population), fixed broadband Internet, Internet bandwidth, mobile Internet (figure 2).

The rating of the countries shows that the Russian Federation occupies 52nd position. Modernization of the national Russian economy due to the introduction of technological green innovations requires the solution of the following strategic objectives: to create a basis for subsequent investment and, first of all, a free financial capital in a fairly large amount; to 
organize a scientific research in a predetermined direction; to prepare a staff according to the specific character of the chosen priority branches of industry, paying special attention to the training of specialists capable of introducing applied research and running specific industry.

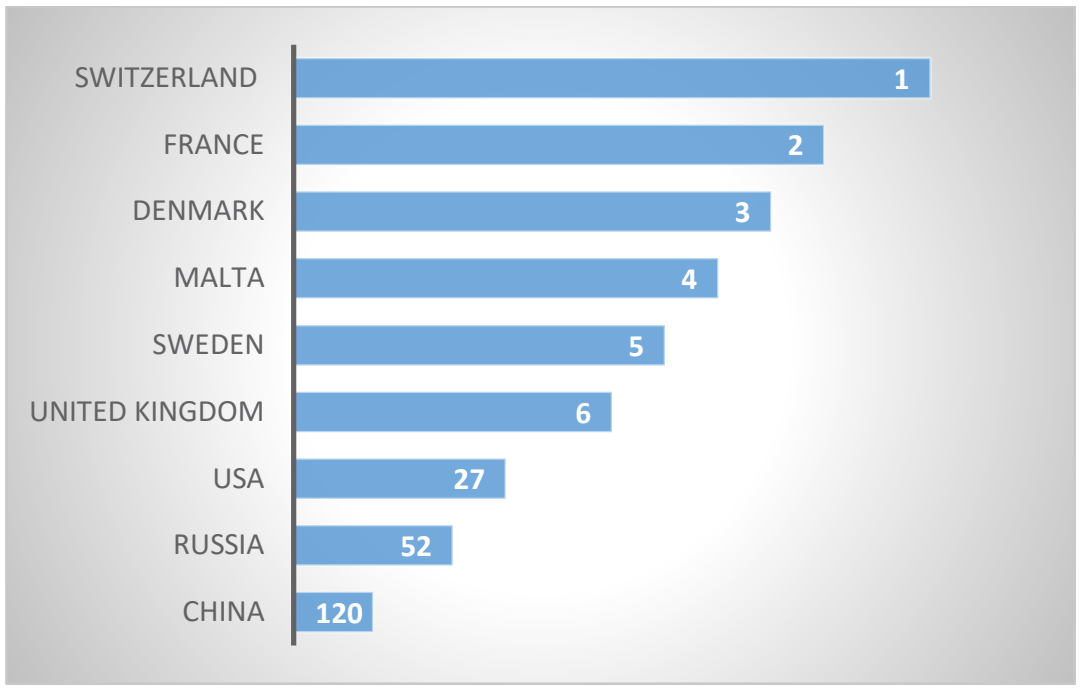

Fig. 1. The rating of countries according to the development of enterprises taking into account the use of innovative opportunities (environmental performance index).

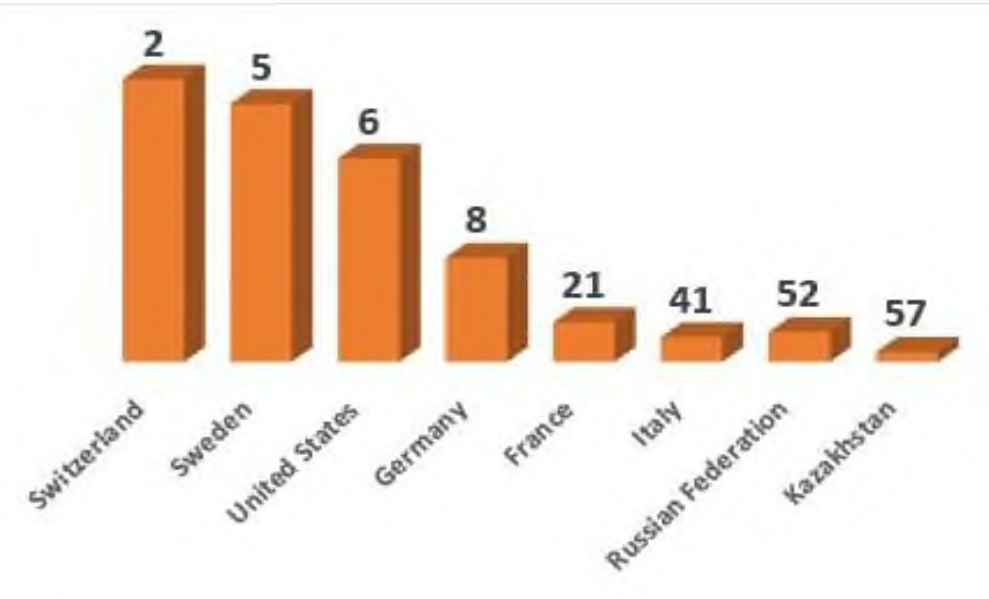

Fig. 2. The rating of the countries according to the level of their preparedness to technological green innovations for the period of 2017-2018 (compiled by the authors).

Summarizing the forgoing, the following should be noted: in the competition wins the one who not only produces new knowledge and technology quicker and better, but the one who can embody them quickly into a certain product and enter the world market with it and the innovative ability will play a dominant and probably decisive role in determining the circle of those participants in the competition who will flourish at the mega level. Innovations will create strategic advantages for companies in the most competitive areas and will become the key to continually improving living standards and quality of life.

Based on the study of methodology "The Global Competitiveness Report" by K. Schwab the points of the decrease in the social and economic indices of Russia were revealed [7]. In our opinion, they have a negative impact on many branches of the Russian green economy, 
including the intensity of local competition, the degree of dominance in the market, the effectiveness of antitrust policy, the influence of taxation on investment incentives, the general tax rate (percentage of profit), the number of procedures to start a business, time (days) to start a business, agricultural policy expenses, prevalence of non-tariff barriers, trade tariffs, a duty percentage, predominance of foreign property. The impact of FDI rules on business, the burden of customs procedures, import percentage of GDP, the degree of customer focus, customer sophistication and top management have influenced its position in competitiveness out of 148 countries for the period of 2017-2019. (Figure 3).

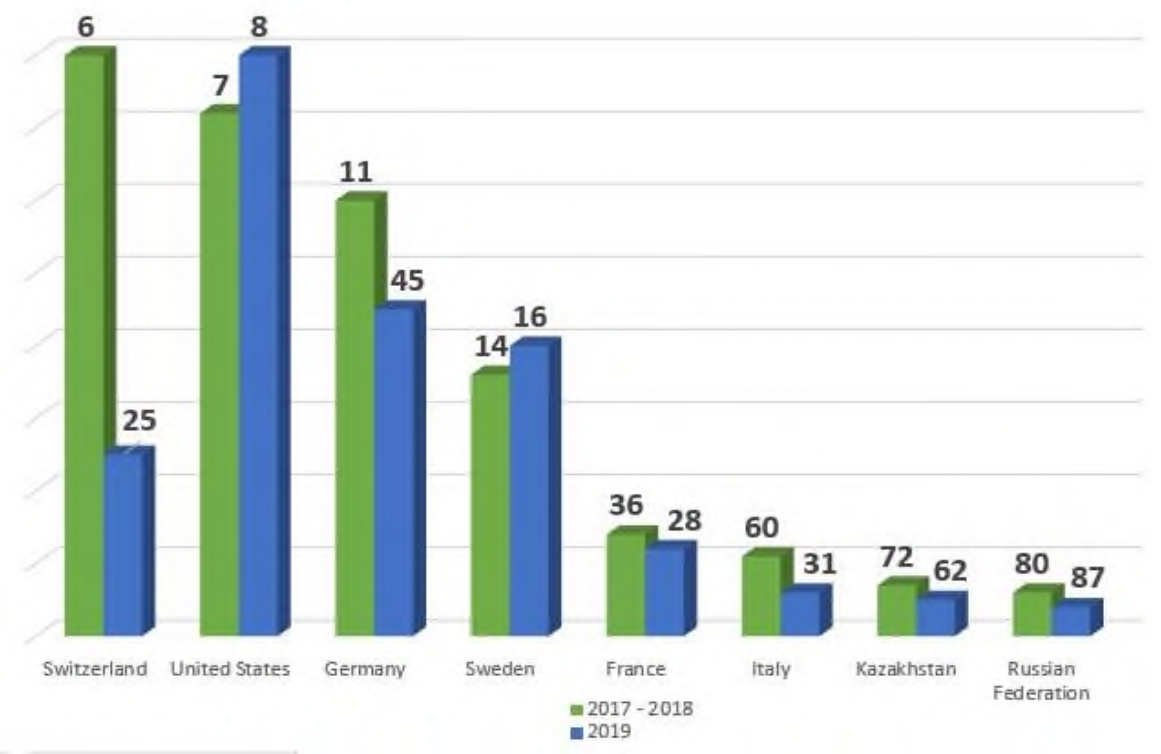

Fig. 3. The competitiveness rating of countries for the period of 2017-2019, in which industry plays the key role in the development of the national green economy (compiled by the authors).

The low level of Russia according to the studied indices requires an active increase in social and economic effectiveness due to the state economic, environmental, regulatory, trade and other policies aimed at stimulating innovative activity and minimizing risks in technological development and commercializing research and development results.

\section{Conclusion}

The modernization of innovation through the introduction of the Japanese method of «Lean manufacturing» in production processes of Russian companies and their certification under the international environmental standard ISO 14000 will enable you to achieve sustainable stability in the country, namely:

- adoption of, a specification of the measures for introduction of international environmental standards in different sectors, control over execution;

- development of environmental policy for the sustainable development of enterprises;

- formation of models for the development of the Russian green economy, taking into account the priority of environmental needs,

- the unification of society on the basis of ecological and humanistic values,

- the formation of a state governed by the rule of law and a civil society that has the ability to protect human rights by showing environmental responsibility to the biosphere. 
The Russian Federation is one of the states for which ensuring stable development on the basis of a green economy is of particular relevance today.

There is a need to introduce innovations, environmental international standards in the activities of each Russian enterprise to meet the environmental requirements of the Russian environmental situation and the general development plans of the Russian Federation aimed at solving socio-economic problems at all levels.

The US Innovation Partnership Initiative program of innovative partnership promotes the introduction of the technological policy closely connected with the cooperation with industry. The experience of the implemented program in the USA shows a focus on mobilizing of all industrial resources of the country (academic community, federal, state and local authorities) in the sphere of innovative development. Based on the results of cross-country monitoring in the field of the development of science and technology respectively, the administration identifies strong and weak points, opportunities and threats for the US industry at the global scientific and technological market and make prompt managerial decisions to improve competitiveness by researching a number of factors.

To ensure the competitiveness of the internal environment of an industrial enterprise (competitive goals, objectives, technologies and workers) it is necessary to solve the problems including those related to maintaining the functioning of the Russian economy in innovative conditions, transforming property relations, a sharp stratification of the society into rich and poor, prevention of the economy criminalization, interaction with other enterprises observing the balance of national interests.

Ensuring the strategic competitiveness of industry can become one of the most important directions for the modernization of the industrial enterprises on their way to the innovative and stable development, contribute to the identification of the most effective "fields of management decisions" to increase business and innovative activity of employees and the enterprise on the whole that will ultimately give an impetus to technological green innovations.

\section{References}

1. R.N. Batavia, Environmental Aspects Of "Green Economy" Economic Growth In Russia, Modern. Innov. Res. 7, 4(28), 142-147 (2016) (In Russ.) https://doi.org/10.18184/20794665.2016.7.4.142.147

2. A. Alchian, H. Demsetz, Production, information costs and economic organization, Amer. Econ. Rev. 62 (5) (1972)

3. R. Bacon, W. Eltis, Britain s economic Problem: Too Few Producers (L: MacMillan, 1976)

4. M. Feldstein, Social security, retirement and aggregate capital accumulation, J. of Polit. Econ. 82 (1974)

5. F. Hayek, The use of knowledge in society, The Nature of the firm: a reader (Cambridge, 1986)

6. D. Parker, Ownership, organizational changes and performance (Political Economy of Privatization, Ed. by T. Clarke, C. Pitelis. L., 1993)

7. K. Schwab, The Global Competitiveness Report 2017-2018. World Economic Forum (2017) https://www.weforum.org/reports/how-to-end-a-decade-of-lost-productivitygrowth

8. E.Y. Cherkesova, E.A. Breusova, E.P. Savchishkina, N.E. Demidova., Competitiveness of the human capital as strategic resource of innovational economy functioning, J. of advan. res. in law and econ. doi: 10.14505/jarle.v7.7(21).11 
9. E. Kolbachev, T. Kolbacheva, Human factor and working out of NBIC technologies, Adv. in Intel. Syst. and Comp. 793, 179-190 (2019) doi: 10.1007/978-3-030-39512-4_46

10. E. Kolbachev, Managing the human factor during the working-out of new technologies and hardware: the reindustrialization conditions, Adv. in Intel. Syst. and Comp. 606, 50-62 (2018) doi: 10.1007/978-3-319-60474-9_5

11. A.A. Tatuev, E.B. Abanokova, N.I. Ovcharova, V.V. Rokotyanskaya, A.Y. Usanov, Social budget and the dynamics of socio-economic development, Espacios 39(4), 38-54 (2018) ISSN: 0798-1015

12. O.A. Tkacheva, E.M. Popova, A.A. Sukhova, E.A. Grevtseva, V.V. Karashchenko, Reward for Innovative Activity of Employees as a Special Item of Financial Accountingof a Globally Oriented Company in the Conditions of the New Economy Formation. Espacios 39(1), 26-34 (2018) ISSN: 0798-1015

13. L.V. Goloshchapova, G.P. Dovlatova, E.I. Zatsarinnaya, O.A. Tkacheva, A.V. Chistyakov, A.S. Agafonov, Identification of strategic instruments to improve the competitiveness of the road industry enterprises, sustainability and strategic development, Intern. J. of Appl. Exerc. Phys. 8(21), 887-895 (2019) doi: 10.30472/ijaep.v8i2.1.566

14. V.V. Prokhorova, V.E. Chernikova, T.U. Anopchenko, L.V. Goloshchapova, N.N. Kulikova, Formation and development of industrial clusters in the socioeconomic regional system, Espacios 39(31), 1-10 (2018) ISSN: 0798-1015

15. E.M. Akhmetshin, K.E. Kovalenko, L.V. Goloshchapova, A.G. Polyakova, E.A. Erzinkyan, G.M. Murzagalina, Approaches to social entrepreneurship in Russia and foreign countries, J. of Entrepr. Ed. 21(S2), 1-10 (2018) ISSN: 1098-8394

16. A.B. Nagoev, V.V. Rokotyanskaya, B.Z. Batova, F.R. Bischekova, M.Z. Hokonova, Mobilization of innovation and investment resources for environmental management in Russian Federation Regions, J. Env. Qual. Manag. 27(4), 47-54 (2018) doi: $10.1002 /$ tqem. 21564

17. G. Romanova, M. Rossinskaya, N. Saveleva, M. Pleshko, A. Pankratenko, Management and monitoring of urban environment in the integrated development of underground space, Adv. in Intel. Syst. and Comp. 692, 1111-1124 (2018) doi: 10.1007/978-3-31970987-1_120

18. M.V. Rossinskaya, S.N. Tsvetcova, V.V. Rokotyanskaya, S.A. Bayzulaev, M.R. Zakhokhova, Management of the socio-ecological and economic systems functioning in a single information space, Espacios 39(27), 1-19 (2018) ISSN: 0798-1015 